\title{
Ten Years of Vegetation Change in Northern California Marshlands Detected Using Landsat Satellite Image Analysis
}

\author{
Christopher Potter \\ NASA Ames Research Center, Moffett Field, USA \\ Email: chris.potter@nasa.gov
}

Received February 24, 2013; revised March 25, 2013; accepted April 19, 2013

Copyright (C) 2013 Christopher Potter. This is an open access article distributed under the Creative Commons Attribution License, which permits unrestricted use, distribution, and reproduction in any medium, provided the original work is properly cited.

\begin{abstract}
The Landsat Ecosystem Disturbance Adaptive Processing System (LEDAPS) methodology was applied to detect changes in perennial vegetation cover at marshland sites in Northern California reported to have undergone restoration between 1999 and 2009. Results showed extensive contiguous areas of restored marshland plant cover at 10 of the 14 sites selected. Gains in either woody shrub cover and/or from a recovery of herbaceous cover that remains productive and evergreen on a year round basis could be mapped out from the image results. However, LEDAPS may not be highly sensitive changes in wetlands that have been restored mainly with seasonal herbaceous cover (e.g., vernal pools), due to the ephemeral nature of the plant greenness signal. Based on this evaluation, the LEDAPS methodology would be capable of fulfilling a pressing need for consistent, continual, low-cost monitoring of changes in marshland ecosystems of the Pacific Flyway.
\end{abstract}

Keywords: Landsat; Marshland; Vegetation; Wetlands; Regrowth; Restoration

\section{Introduction}

Marshland can be defined as an area of land where the soil is saturated at least seasonally and which supports hydrophilic (water-loving) vegetation cover, either submergent, floating, emergent, or shoreline forms [1]. Since 2000 , more than 300 wetland restoration projects for Northern California marshlands have been commissioned, many having resulted from partnerships between state and federal agencies, local citizen groups, and private sector/business [2].

The numerous wetland restoration projects undertaken in the San Francisco and Central Valley regions were intended to restore habitat for waterfowl, as well as improving flood control and increasing public access. About 60 percent of the waterfowl on the West Coast use the Pacific Flyway in the winter [3]. Dozens of species of migratory birds return to their ancestral wintering grounds to feed and rest in the freshwater marshes, shallow lakes, and river systems of Northern California.

California's Natural Resources Agency (CNRA) has recommended that the state take steps to establish a comprehensive monitoring program that incorporates elements of mapping and inventory, rapid screening assessment, and intensive site-specific evaluation [4]. This program would be established with formal input from the State's wetlands conservation community including, but not limited to, Joint Ventures and non-governmental organizations. Monitoring elements would be designed to answer broad environmental questions and site-specific questions related to development projects. This approach would allow for comparisons of compatible data for the evaluation of restorations project performance in light of overall regional patterns and trends.

In this study, one element of such a monitoring program was assessed, namely the use of satellite image data to detect wetland area loss or gain. The Landsat satellite imagery was analyzed and the results evaluated from the years 1999 and 2009 to provide a detailed record of 10 years of vegetation restoration (or disturbance) for selected marshlands within the Northern California Pacific Flyway region. The analysis of Landsat imagery over time to map all potential changes in land cover along the $\mathrm{Pa}$ cific Flyway marshlands at a regional scale is a unique approach to detect and categorize multiple agents of change simultaneously, including human-induced restoration or development. 


\section{Regional Geography of the Study Area}

Prior to the Gold Rush of the mid-1800s, Northern California was a region of vast aquatic habitats, including the Sacramento River Delta, vernal pools, and tidal marshes along San Francisco Bay. By the 1930s, 90 percent of California's wetlands had been lost to development [3]. San Francisco Bay Area marshes were turned into salt ponds. Large parts of the Delta were converted into agricultural fields and grazed pastures.

California presently has approximately 2.9 million acres of wetlands [4]. About 38 percent of the State's wetlands are found in the San Francisco Bay Delta (Figure 1) and Central Valley regions. Freshwater wetlands are the most abundant type in California, with 60 percent of the state's total wetland area found in vernal pools, marshes, wet meadows, fens, playas, seeps and springs.

\section{Methods}

The LEDAPS Disturbance Index (DI) was described by Masek et al. [5] as a transformation of the Landsat Tasseled-Cap data space [6-8], specifically designed for sensitivity to perennial (i.e., evergreen) shrubland, woodland, and forest cover change. The Tasseled-Cap brightness, greenness, and wetness indices are standard transformations of the original Landsat spectral bands, effectively capturing the three major axes of spectral variation across the solar reflective spectrum. As demonstrated by Healey et al. [9], the DI is a simple and effective means of tracking vegetation disturbance and recovery across ecosystems dominated by perennial cover types. Unlike simple visible/near-infrared indices (e.g. the Normalized Difference Vegetation Index-NDVI), the LEDAPS DI incorporates Tasseled-Cap wetness, thereby including

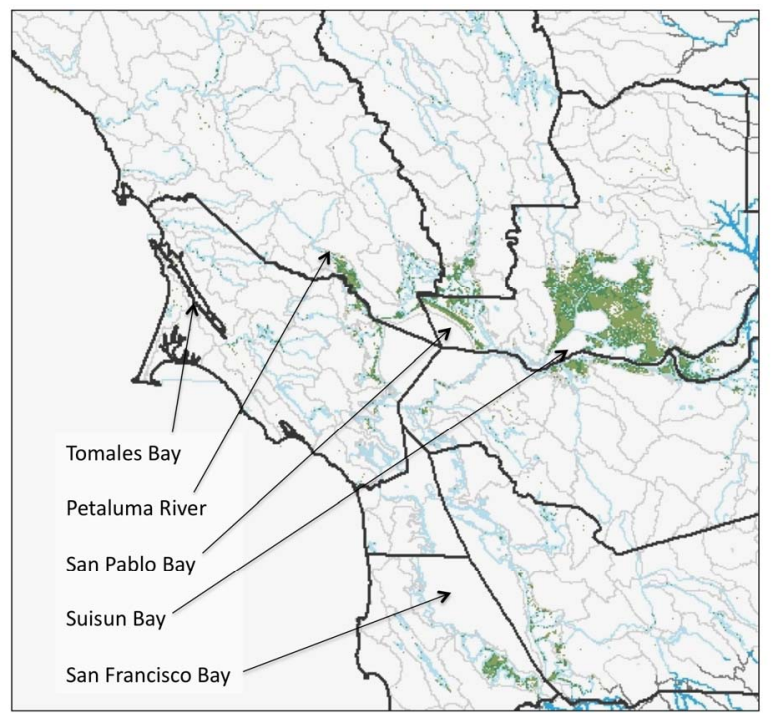

Figure 1. Map of Northern California wetlands (in green shades) for the San Francisco Bay Area, from NLCD (2001). information from the shortwave infrared wavelength, which was shown to be valuable for assessing changes in perennial vegetation structure [10].

The LEDAPS DI quantifies the normalized spectral distance of any given pixel from a nominal "dense woody vegetation" class to a "bare soil" class. The DI is calculated using the Tasseled-Cap (brightness-greenesswetness) indices for Landsat images [8]:

$$
\mathrm{DI}=B^{\prime}-\left(G^{\prime}+W^{\prime}\right)
$$

where $B^{\prime}, G^{\prime}$, and $W^{\prime}$ represent the Tasseled-Cap brightness, greenness, and wetness indices normalized by a dense woody vegetation index result identified for each Landsat scene. For example:

$$
B^{\prime}=(B-\mu B) / \sigma B
$$

where $\mu B$ is the mean Tasseled-Cap brightness index of the dense woody vegetation class for a particular Landsat scene, and $\sigma B$ is the standard deviation of brightness within the dense woody vegetation class for that same scene. In effect, the DI measures the spectral distance of a given pixel from the dense woody vegetation "centroid" for that scene, in units of within-class standard deviation. Since LEDAPS DI values are based on the statistics of woody vegetation cover reflectance from individual scenes, the DI is relatively insensitive to variability in solar geometry between scenes, and lessens the effect of seasonal vegetation variability among Landsat image dates.

Given the population of mature perennial vegetation pixels identified from recent land cover map products, the mean and standard deviation of each Tasseled-Cap component for the class were calculated. Each TasseledCap image plane was then normalized as in Equations (1) and $(2)$. The difference in DI ( $\Delta \mathrm{DI})$ was next calculated between 1999 and 2009. Large positive values of $\Delta \mathrm{DI}$ have been shown be associated with a major disturbance event such as wildfire, whereas large negative $\Delta \mathrm{DI}$ values frequently correspond to regrowth of perennial woody vegetation following disturbance [5].

Thresholds were next applied to the $\Delta \mathrm{DI}$ values to identify the highest probable areas of ecosystem disturbance or vegetation regrowth/restoration. These $\Delta \mathrm{DI}$ thresholds were determined using wildfire perimeter boundaries mapped on an annual basis by the California Department of Forestry, Fire and Resource Assessment Program (FRAP), with contributions from the USDA Forest Service, the Bureau of Land Management, and the National Park Service (data available at http://frap.cdf.ca.gov). Manual adjustments of these thresholds were carried out across Central California to optimize the spatial correspondence between $\Delta \mathrm{DI}$ for areas burned by wildfire before 1999 (regrowth pixels) and those burned between 1999 and 2009 (disturbed pixels). 
Since short-term land use transformations may be inadvertently identified by $\Delta \mathrm{DI}$, particularly agricultural rotation patterns and fallowing of cropland, we routinely excluded these annual transitions for further evaluations by screening LEDAPS results with a cropland/noncropland mask based on USDA National Agricultural Statistics Service (NASS), California Cropland Data Layer (CDL) from 2010 (available at http://nassgeodata. gmu.edu/CropScape). The CDL is a raster, georeferenced, crop-specific land cover data layer with a ground resolution of 30 meters. The CDL is produced using satellite imagery from the Indian Remote Sensing RESOURCESAT-1 (IRS-P6) Advanced Wide Field Sensor (AWiFS) collected during the current growing season. Additional land cover maps were used as zonal layers for classifying LEDAPS results, including: the United States Geological Survey (USGS) National Elevation Dataset (NED), the USGS National Land Cover Database 2001 (NLCD 2001), and the National Aeronautics and Space Administration (NASA) Moderate Resolution Imaging Spectroradiometer (MODIS) 250-meter resolution 16-day vegetation index composites.

\section{Results}

Changes in perennial emergent vegetation cover between 1999 and 2009 from LEDAPS analysis were mapped out for 14 documented marshland restoration sites in Northern California (Table 1). The restoration sites were selected for this study first on the basis of start date, which needed to be before 2008 to allow for restoration effects to be detected, and second on the basis of the size of the area restored, with the largest projects given preference. Each of these restoration projects was examined in detail below for LEDAPS results.

\subsection{South Bay Salt Ponds}

Since mid-1990s, the area of tidal marsh in southernmost San Francisco Bay has expanded by more than 20\% [11]. This expansion occurred as marsh vegetation colonized former mudflats [12]. Three South Bay sites were examined for LEDAPS results: Calaveras Marsh is a large fringe marsh that has grown-in significantly with over the last 20 years with Spartina foliosa [12]. Ogilvie Island has also grown significantly during that period. Pond A21 was a salt pond restored under the South Bay Salt Pond Restoration Project and has shown extensive floral colonization since 2004 when it was breached.

Results from the LEDAPS analysis for change between 1999 and 2009 showed restored plant cover around these salt marshes (Figure 2). Dark-blue shaded pixels were those detected as expanding (or restored) plant cover between 1999 and 2009 in the central and southern portions of Calaveras Marsh and Ogilvie Island. Conversely,
South Bay Salt Ponds

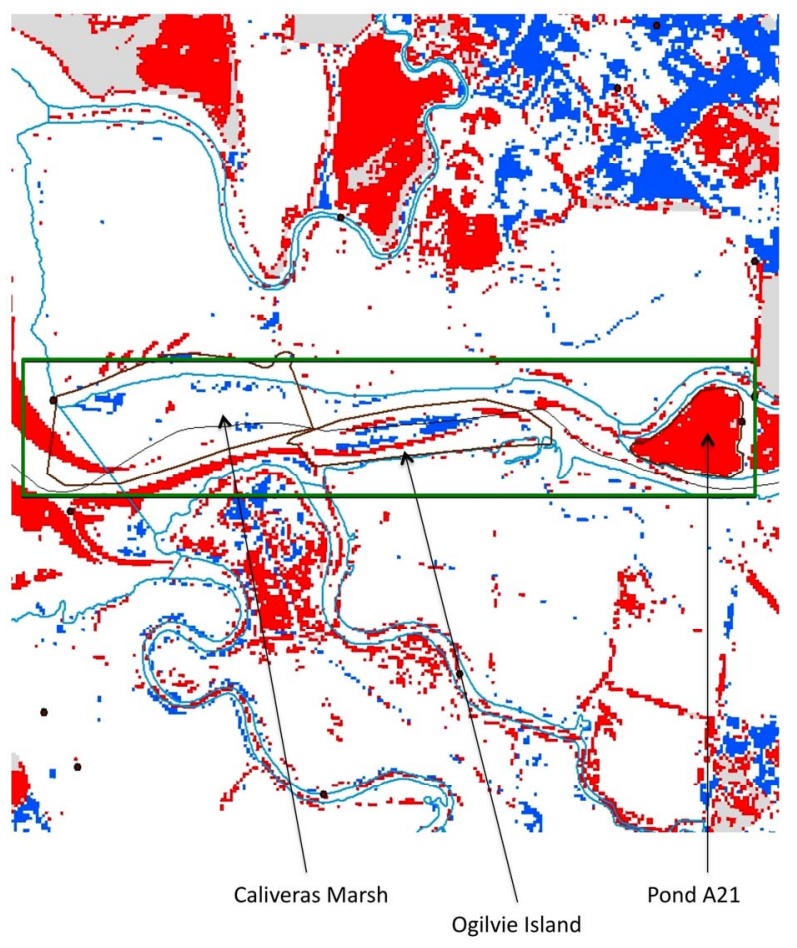

Figure 2. Results from LEDAPS difference analysis of Landsat imagery (30-meter pixel resolution) between 1999 and 2009 for three South Bay marsh sites. Dark-blue shaded pixels were detected as expanding or restored perennial plant cover, whereas red shaded pixels were detected as disturbed or decreasing plant cover. Shoreline boundaries were delineated in light blue lines. Documented restoration areas were delineated in green lines (from references cited in this paper).

red shaded pixels were detected by the LEDAPS DI method as disturbed or decreasing plant cover between 1999 and 2009 throughout the Pond A21 area.

\subsection{Yolo Bypass Wildlife Area}

Beginning in 1989, the Yolo Basin Foundation began an effort to establish a Wildlife Area in the Yolo Bypass. In 1992, the California Department of Fish and Game began acquiring property for this purpose within the Bypass. Since 1997, the Yolo Bypass Wildlife Area (YBWA) has grown to over 16,000 acres, one of the largest publicprivate restoration projects in the nation [13]. Results from the LEDAPS analysis for change between 1999 and 2009 showed restored perennial marshland plant cover in the "South Unit" of the YBWA (Figure 3).

\subsection{Napa Sonoma Marshes}

The marshland between the Napa River and Sonoma Creek in the north San Pablo Bay region is called the Napa-Sonoma Marshes Wildlife Area (NSMWA). The Napa-Sonoma Marsh historically encompassed more than 
Table 1. Northern California marshland restoration sites selected for LEDAPS evaluation from 1999 to 2009 , sorted by area from highest to lowest.

\begin{tabular}{|c|c|c|c|c|c|}
\hline Site Name & Status & Latitude & Longitude & Area (acres) & Started \\
\hline South Bay Salt Ponds & In-progress & $38.6164^{\circ} \mathrm{N}$ & $-122.1377^{\circ} \mathrm{W}$ & 14,657 & 2004 \\
\hline Yolo Bypass Wildlife Area & Completed & $38.4638^{\circ} \mathrm{N}$ & $-121.5989^{\circ} \mathrm{W}$ & 8000 & 1998 \\
\hline Napa Sonoma Marshes & In-progress & $38.2027^{\circ} \mathrm{N}$ & $-122.3425^{\circ} \mathrm{W}$ & 7322 & 1995 \\
\hline Skaggs Island & In-progress & $38.1937^{\circ} \mathrm{N}$ & $-122.3713^{\circ} \mathrm{W}$ & 4167 & 2006 \\
\hline Bel Marin Keys Unit V & In-progress & $38.0758^{\circ} \mathrm{N}$ & $-122.5013^{\circ} \mathrm{W}$ & 1564 & 2006 \\
\hline Bair Island & In-progress & $37.5258^{\circ} \mathrm{N}$ & $-122.2326^{\circ} \mathrm{W}$ & 1385 & 2006 \\
\hline Ryer Island & In-progress & $38.0835^{\circ} \mathrm{N}$ & $-122.0171^{\circ} \mathrm{W}$ & 930 & 2006 \\
\hline American Canyon & Completed & $38.1704^{\circ} \mathrm{N}$ & $-122.2766^{\circ} \mathrm{W}$ & 620 & 2006 \\
\hline Elsie Gridley & In-progress & $38.2962^{\circ} \mathrm{N}$ & $-121.8076^{\circ} \mathrm{W}$ & 441 & 2005 \\
\hline Sonoma Baylands & Completed & $38.1205^{\circ} \mathrm{N}$ & $-122.4823^{\circ} \mathrm{W}$ & 350 & 1996 \\
\hline Leonard Ranch Wetlands & Completed & $38.1270^{\circ} \mathrm{N}$ & $-122.4823^{\circ} \mathrm{W}$ & 334 & 2003 \\
\hline Petaluma Marsh & In-progress & $38.1803^{\circ} \mathrm{N}$ & $-122.5721^{\circ} \mathrm{W}$ & 108 & 2003 \\
\hline
\end{tabular}

Data Sources: http://www.californiawetlands.net/tracker/ba/list and the National Park Service. Area in hectares is equal to acres times 0.4 .

\section{Yolo Bypass Wildllife Area}

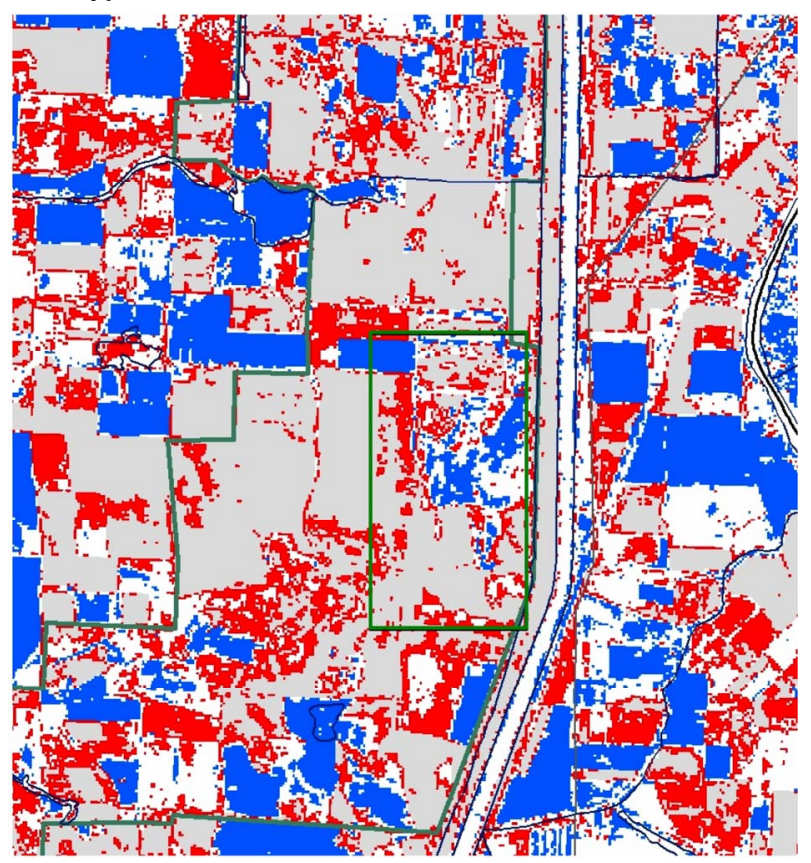

Figure 3. Results from LEDAPS difference analysis between 1999 and 2009 for the Yolo Bypass Wildlife Area.

38,000 acres. Cargill Salt Company operated the area as commercial salt ponds until the mid-1990s. The remaining salt ponds, cropland, and pasture in the areas were disked in the restored NSMWA to prevent tidal and fluvial inundation under normal conditions [14]. Tidal influence was restored to Pond 2A, a 525-acre abandoned salt pond, through designed levee breaches in 1995 and 1997. Within one year of the breach, total vegetation cover went from less than $10 \%$ to $25 \%$ - $30 \%$, and within 5 years, vegetation cover approached $90 \%$. The dominant species include prairie bulrush (Scirpus maritima), California cord grass, pickle weed, and cattail [14].

Results from the LEDAPS analysis for change between 1999 and 2009 showed restored perennial vegetation cover in Ponds 6 and 7, but not in the earlier restored salt ponds of the NSMWA (Figure 4). Ponds 3-5 were detected with a decline in perennial vegetation cover. The plants in most of the restored pond areas of NSMWA may be seasonal and largely herbaceous in grown (rather than perennial and woody), making detection of regrowth less likely with the LEDAPS methodology.

\subsection{Skaggs Island}

Located just to the west and across Sonoma County boundary from the NSMWA is Skaggs Island on the northern shore of San Pablo Bay. The US Navy owns three quarters of Skagg Island, with the remainder privately operated as the Haire Ranch. Tidal marshlands were restored starting in 2006. Results from the LEDAPS analysis detected little change between 1999 and 2009, with the exception of small areas of restored perennial vegetation cover, in patches 1 to 6 hectare area throughout Skaggs Island (Figure 5).

\subsection{Montezuma Wetlands}

This project location is adjacent to Montezuma Slough 
Napa Sonoma Marshes

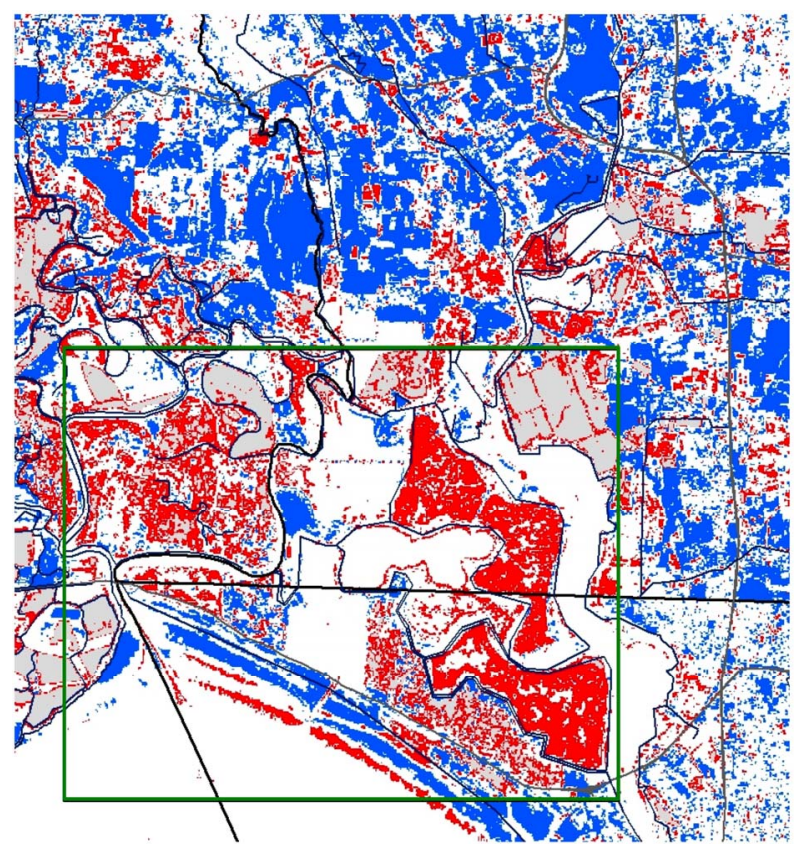

Figure 4. Results from LEDAPS difference analysis between 1999 and 2009 for Napa Sonoma Marshes.

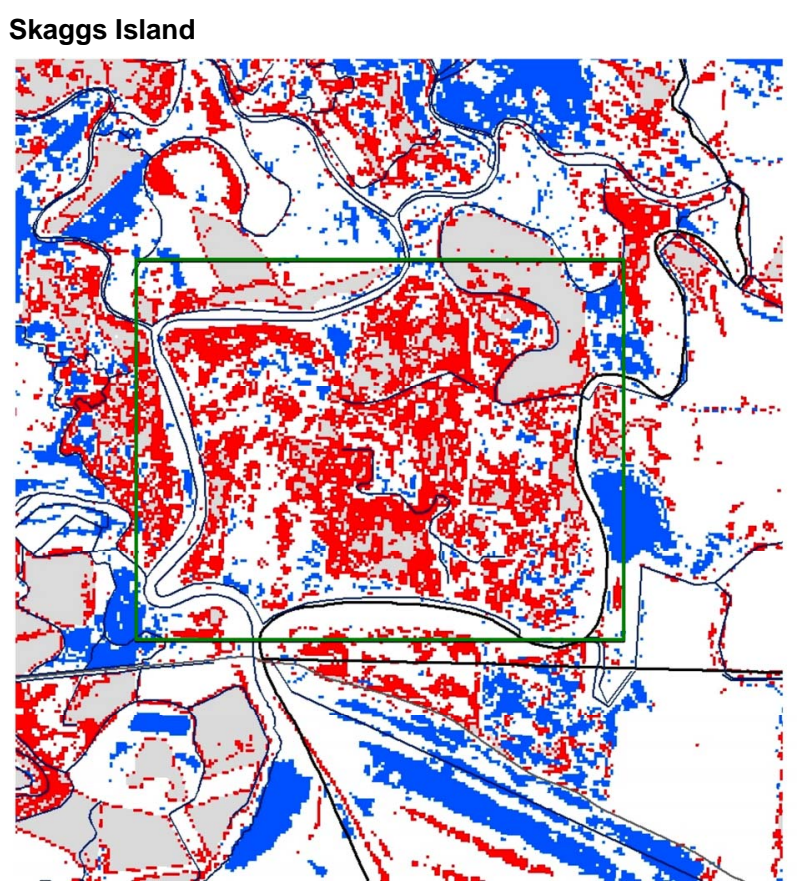

Figure 5. Results from LEDAPS difference analysis between 1999 and 2009 for Skaggs Island.

and Suisun Bay in Solano County. Restoration involved transporting millions of cubic meters of dredged, cleaned sediment into the disked marshlands that were previously used for livestock grazing. Montezuma was the first privately sponsored (by Levine-Fricke) wetland restoration project in the nation. Results from the LEDAPS analysis for change between 1999 and 2009 showed restored perennial vegetation on over 300 hectares of marshland within the project area (Figure 6). The areas detected as restored vegetation do not however correspond in a consistent pattern to documented gains or losses in Phase 1 of the Montezuma Wetlands restoration, which was previously ruderal habitat/grasslands with small amounts of seasonal wetlands that has been mostly transformed into either exposed mud or ponded water (R. Bonnefil, personal communication).

\subsection{Bel Marin Keys Unit V}

This restoration project was located on Pacheco Pond and Novato Creek. A flood management levee had been built through the site to separate the tidal wetland portion from the seasonal wetland area and to protect the lagoon from extreme tides [15]. The site has not yet been fully breached for tidal action, but partial restoration has been documented with muted tidal flow through culverts. Results from the LEDAPS analysis for change between 1999 and 2009 showed areas of renewed perennial vegetation cover in the tidal wetland areas to the south of Bel Marin Keys and also in the non-tidal wetland adjacent to Hamilton Air Force Base (Figure 7).

\subsection{Bair Island}

This restoration project was located adjacent to the San Francisco Bay in San Mateo County. Bair Island was historically part of a large complex of tidal marshes and

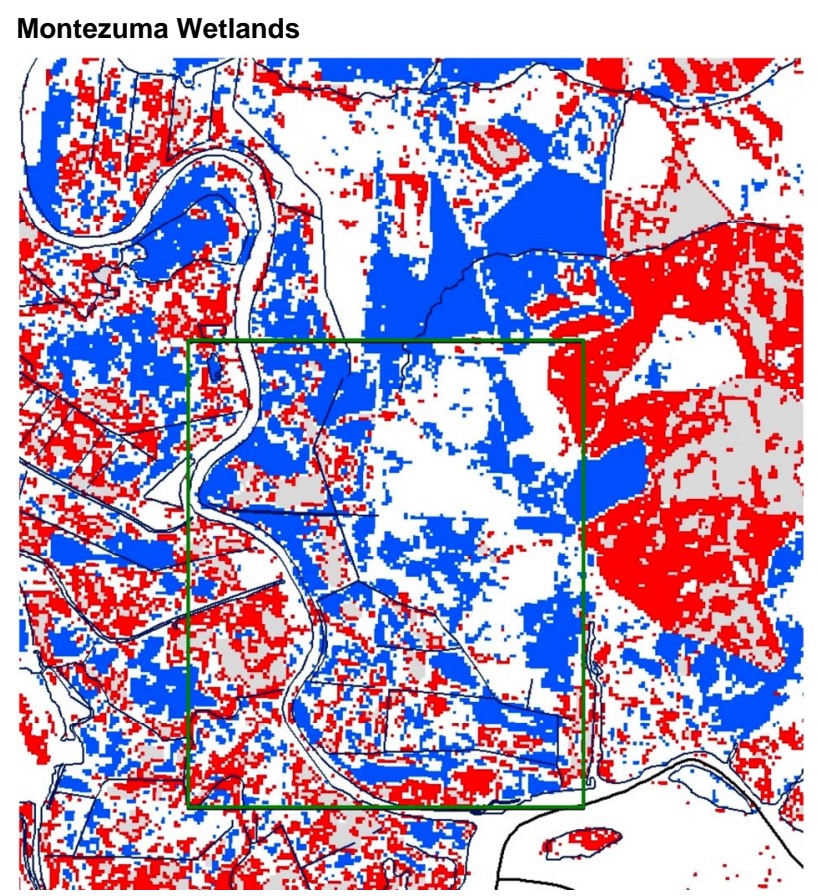

Figure 6. Results from LEDAPS difference analysis between 1999 and 2009 for Montezuma Wetlands. 
Marin Keys Unit V

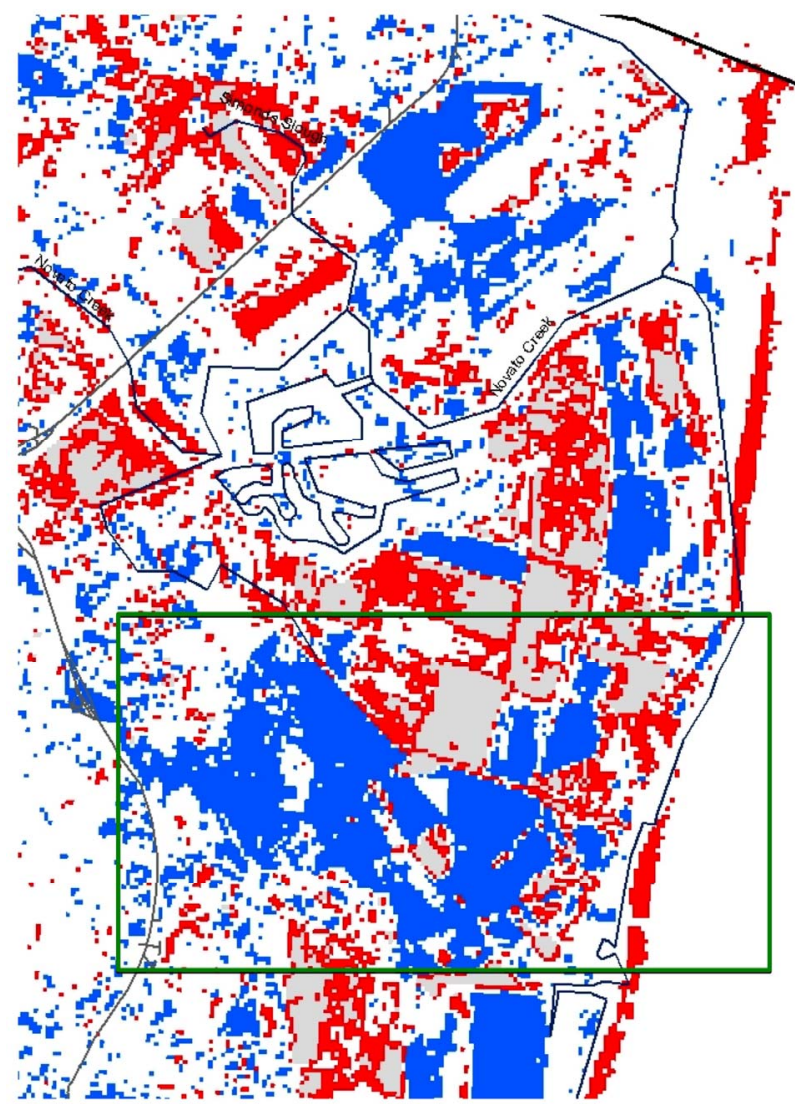

Figure 7. Results from LEDAPS difference analysis between 1999 and 2009 for Bel Marin Keys Unit V.

mud flats within the drainage of Bay and Belmont Sloughs [16]. The island was used for salt evaporation ponds starting in 1946, and remained in production until 1965. The California Department of Fish and Game (CDFG) and the Don Edwards San Francisco Bay National Wildlife Refuge acquired portions of the island thereafter for restoration [17]. Results from the LEDAPS analysis for change between 1999 and 2009 showed restored perennial vegetation over the entire restoration areas of Outer Bair (Figure 8). There was much less regrowth detected over Inner Bair and Middle Bair areas, whose dikes were yet to be breached in 2009. The LEDAPS red pixel areas in the southeastern section of the restoration project area were confirmed as diminished perennial marchland vegetation cover during the past decade due to lack of hydrologic connection to the San Francisco Bay (J. Bourgeois, personal communication).

\subsection{Ryer Island}

One of the completed restoration sites within Suisun Marsh was the Ryer Island project. Restoration construction mainly involved breaching and re-alignment of flood protection levees. Only part of the island was leveed and restored, leaving a reference area adjacent to the restored site [18]. Results from the LEDAPS analysis for change between 1999 and 2009 showed restored perennial vegetation cover over small ( 1 to 5 hectare) patches along the northern edge of Ryer Island (Figure 9). Loss of perennial

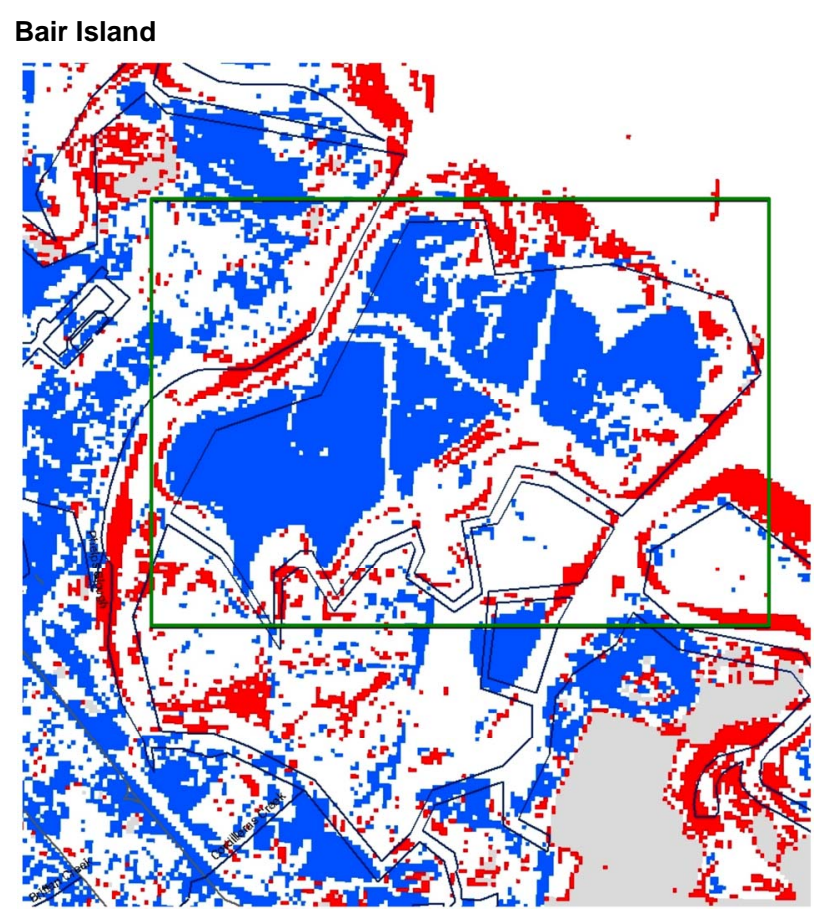

Figure 8. Results from LEDAPS difference analysis between 1999 and 2009 for Bair Island.

Ryer Island

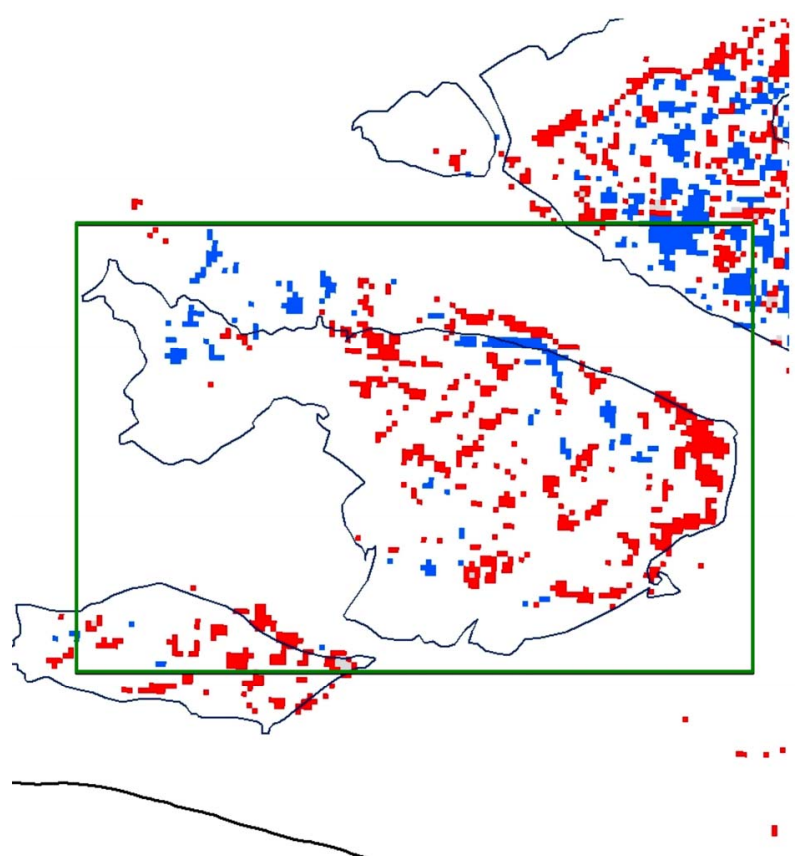

Figure 9. Results from LEDAPS difference analysis between 1999 and 2009 for Ryer Island. 
vegetation cover was detected over slightly larger areas, mainly on the western side of the island.

\subsection{American Canyon}

Tidal wetlands were restored from former salt ponds by levee breaches on the east side of the Napa River adjacent to the city of American Canyon [19]. Results from the LEDAPS analysis for change between 1999 and 2009 showed restored perennial vegetation over nearly 200 hectares of wetlands on the east side of the Napa River adjacent to the city of American Canyon (Figure 10).

\subsection{Giacomini Wetland}

The Giacomini Wetland Restoration Project was located on the southern end of Tomales Bay, just to the west of Point Reyes Station in Marin County. The former dairy ranch was restored to tidal wetlands and floodplain. Restoration included removing levees, tidegates, culverts, and agricultural infrastructure, filling in drainage ditches, recreating tidal sloughs and creeks, and shifting creeks into historic alignments [20]. Results from the LEDAPS analysis for change between 1999 and 2009 showed restored perennial vegetation over nearly all of the 110 hectares of the Giacomini Wetland (Figure 11).

\subsection{Elsie Gridley}

The Elsie Gridley Mitigation Bank was established for the purpose of providing offsite mitigation opportunities for vernal pool grassland and riparian habitats, as well as a number of associated rare and endangered species. The

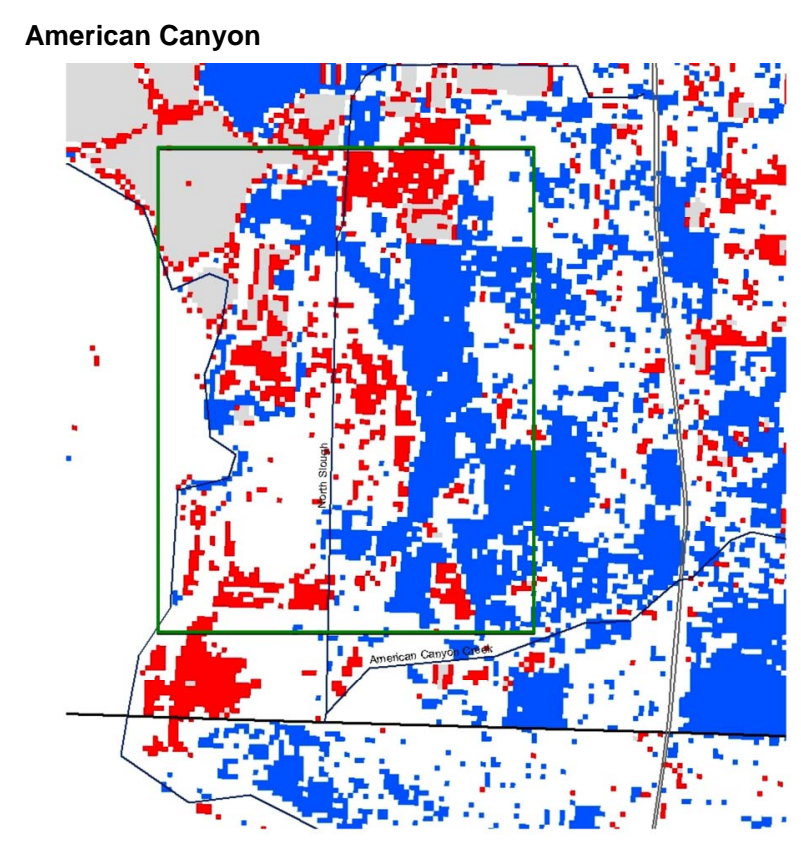

Figure 10. Results from LEDAPS difference analysis between 1999 and 2009 for American Canyon.

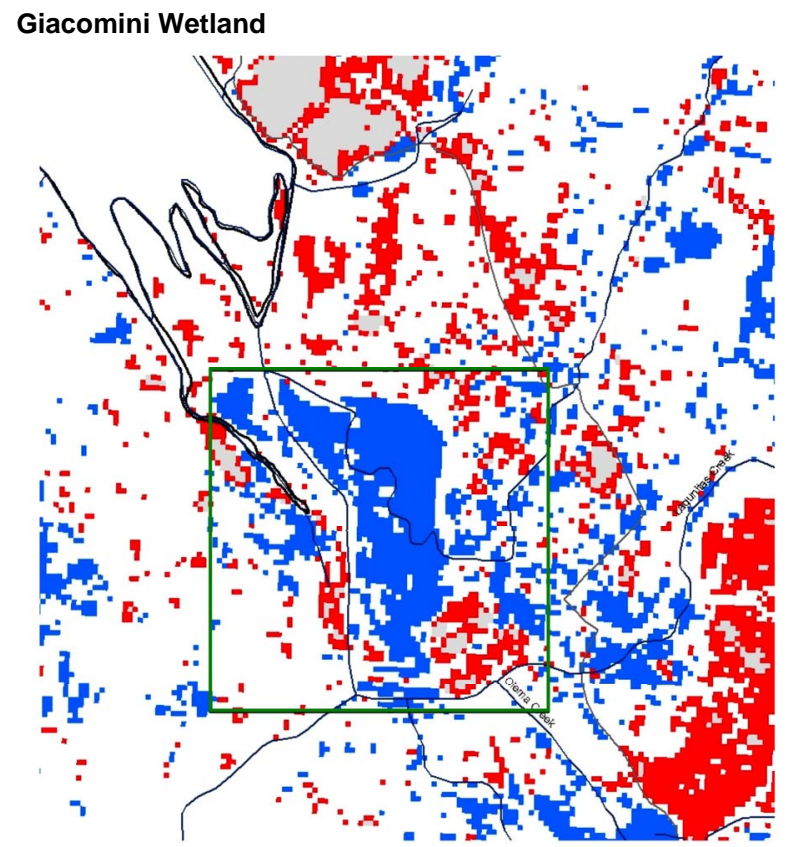

Figure 11. Results from LEDAPS difference analysis between 1999 and 2009 for the Giacomini Wetland.

restored Elsie Gridley preserve site was located in eastern Solano County, south of the City of Dixon and adjacent to the Solano Land Trust's Jepson Prairie Preserve. Former pasturelands were restored to vernal pool grassland and riparian habitats. Results from the LEDAPS analysis for change between 1999 and 2009 showed restored perennial vegetation over nearly the entire 500 hectares of the Elsie Gridley Mitigation Bank (Figure 12).

\subsection{Sonoma Baylands}

The Sonoma Bayland Wetland Demonstration Project was carried out on formerly diked farmland at the mouth of the Petaluma River in southern Sonoma County. Restoration of tidal marsh included breaching the levee separating the site from the Petaluma River, placement of dredged material, and restoration of tidal action from San Pablo Bay [21]. Curved berms were designed as wind-wave barriers to enhance additional sediment deposition. Results from the LEDAPS analysis for change between 1999 and 2009 showed restored perennial vegetation cover over only small portions (1 - 5 hectares) of Sears Point. A larger section (150 hectares) or regrowth in marshlands was detected to the northwest near Black John Marsh (Figure 13).

\subsection{Leonard Ranch Wetlands}

This site was located directly north of the Sonoma Baylands Tidal Marsh on San Pablo Bay in southern Sonoma County. Restoration included removing most agricultural activities from the ranchlands, along with construction of 


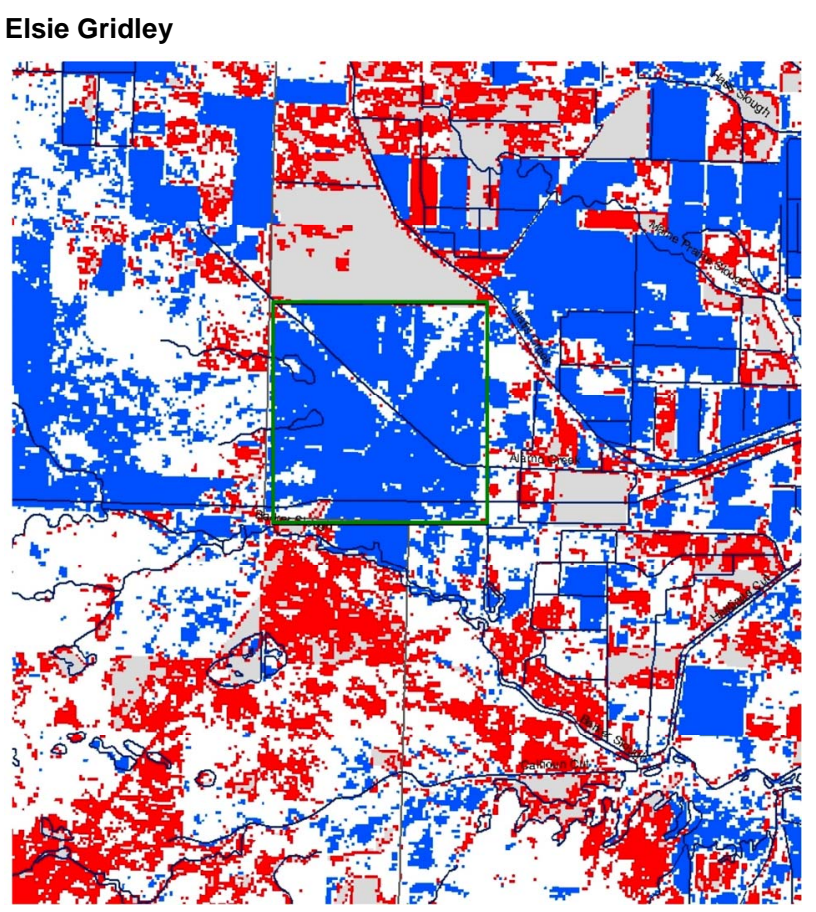

Figure 12. Results from LEDAPS difference analysis between 1999 and 2009 for the Elsie Gridley Mitigation Bank.

Sonoma Baylands and Leonard Ranch Wetlands

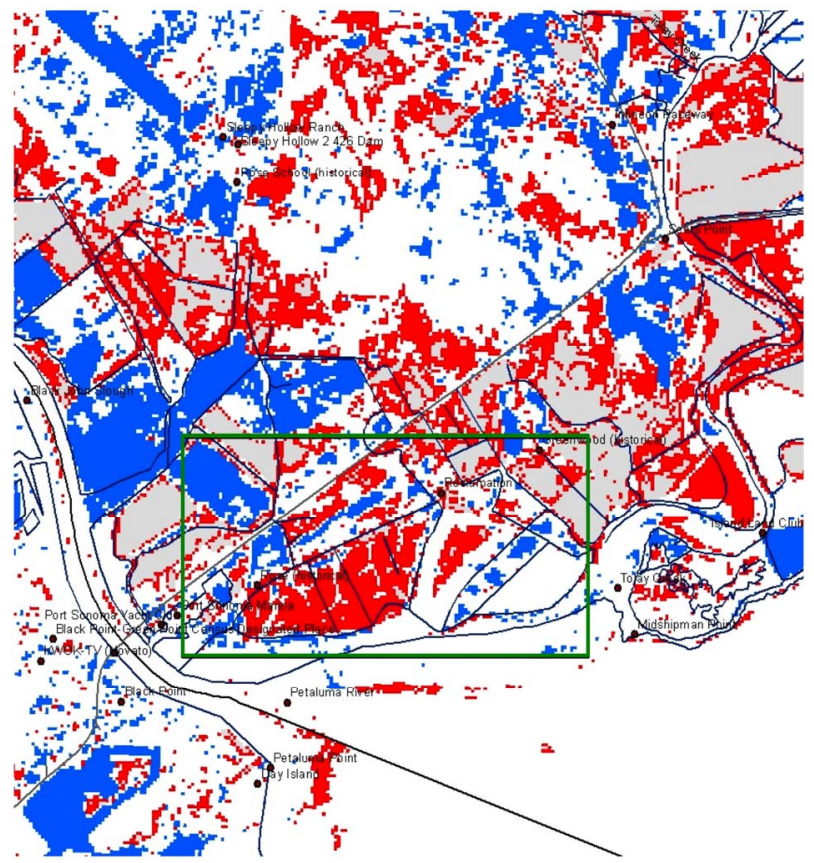

Figure 13. Results from LEDAPS difference analysis between 1999 and 2009 for the Sonoma Baylands and Leonard Ranch Wetlands.

passive water control structures. Results from the LEDAPS analysis for change between 1999 and 2009 showed restored perennial vegetation over nearly 15 hectares of Leonard Ranch (Figure 13).

\subsection{Petaluma Marsh}

This project involved restoration of formerly diked baylands by removal of levees west of the Petaluma River at the Marin-Sonoma County border. Results from the LEDAPS analysis for change between 1999 and 2009 showed restored perennial vegetation over nearly 70 hectares (a majority coverage) of Petaluma Marsh (Figure 14).

\section{Discussion}

The results presented in this study show that the LEDAPS methodology can detect expected changes in perennial emergent vegetation cover in restored marshlands, due to gains of either woody shrub cover or from recovery of herbaceous cover that remains productive and evergreen on a year round basis. Limitations of the methodology are worth noting however. LEDAPS may not be highly sensitive changes in wetlands that have been restored mainly with seasonal herbaceous cover (e.g., vernal pools), due to the ephemeral nature of the LEDAPS change signal and its potential to vary in magnitude by plus or minus several weeks from one year to the next with the weather in such wetland areas. The method was neither developed nor intended for use in detection and mapping of changes in the water levels of lakes, reservoirs, or floodplains or in the extent of (open water) surface inundation

Based on the evaluation of 14 wetland restoration case studies presented above, LEPAPS results were the most

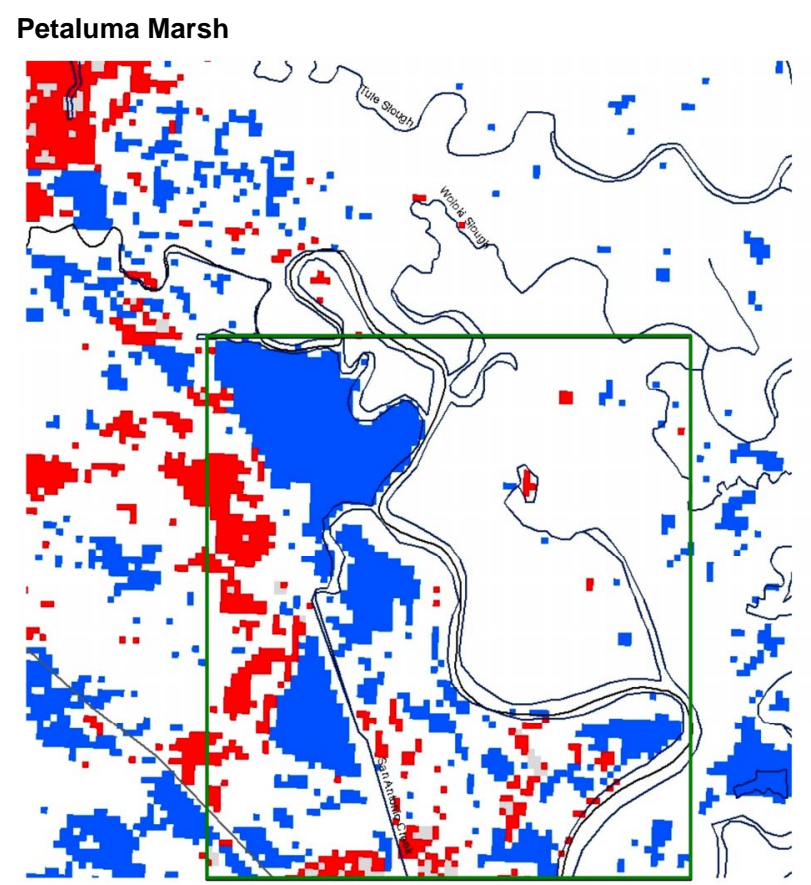

Figure 14. Results from LEDAPS difference analysis between 1999 and 2009 for the Petaluma Marsh. 
conclusive in terms of confirming reported regrowth of emergent vegetation cover in 10 of the marshland project sites: South Bay Salt Ponds, Yolo Bypass Wildlife Area, Napa Sonoma Marshes, Bel Marin Keys, Bair Island, American Canyon, Giacomini Wetland, Elsie Gridley, Leonard Island, and Petaluma Marsh.

Not all wetland restoration projects may have been designed (nor have had sufficient time) to achieve the outcome of measurable gains in perennial vegetation cover. Based on satellite imagery, this appears to be the case for the following restoration projects: Skaggs Island, Montezuma Wetlands, Ryer Island, and Sonoma Baylands. The interpretation of LEDAPS results in these projects was further complicated by the potential for loss of previous emergent vegetation cover soon after restoration began, resulting from extensive subsidence that typically follows the return of more natural tidal mudflats and inundation dynamics to the marshlands (C. Wilcox, personal communication).

For any project area, LEDAPS results can nonetheless be used to assess those sub-areas within the marshland that have shown partial restoration of perennial vegetation. In addition, the image products may be used potentially to discover important associations between regrowth and topographic, geochemical, and biological attributes of interest within the marshlands. This kind of sub-area analysis would require measurement and mapping of such attributes at a resolution of several meters over the majority of the wetland area. If such measurement data do not exist, LEDAPS results may prove valuable in the design of new field sampling schemes for geochemical and biological attributes of interest.

To expand the LEDAPS methodology for routine coverage of all marshland areas in the California Pacific Flyway north of Monterey Bay, it is estimated that processing of ten different Landsat scenes per year would be required. Automated scripting can make the procedure routine and cost-effective. The use of statewide wetland boundary masks will further streamline the Landsat processing time, and facilitate post-processing analysis of net changes in vegetated marshland areas. New algorithms can be developed to automatically identify and rank the largest contiguous areas of change (either regrowth or disturbance) in the state for user-defined buffer zones around established wetland boundaries.

\section{Acknowledgements}

This work was supported mainly by funds from NASA Ames Research Center. The author thanks (in alphabetical order): Rachel Bonnefil, John Bourgeois (State Coastal Conservancy), Brian Fulfrost, Tom Gandesbery (State Coastal Conservancy), Lorraine Parsons (Point Reyes National Seashore), Christina Sloop (San Francisco Bay Joint Venture), Carl Wilcox (California Department of
Fish and Wildlife), and Greg Yarris (US Fish and Wildlife Service) for assistance with image interpretations and historical information on marshland restoration results.

\section{REFERENCES}

[1] California Regional Water Quality Control Board, "Policy and Guidelines on the Use of Wastewater to Create, Restore, Maintain, and/or Enhance Marshlands, San Francisco, Bay Region," 1977.

http://www.waterboards.ca.gov/sanfranciscobay

[2] California Wetlands Tracker, "California Wetlands Portal," 2012.

http://www.californiawetlands.net/tracker/ba/list

[3] R. M. Wilson, "Seeking Refuge: Birds and Landscapes of the Pacific Flyway," University of Washington Press, Seattle, 2010.

[4] California Natural Resources Agency (CNRA), "State of the State's Wetlands, 10 Years of Challenges and Progress," California Natural Resources Agency, Sacramento, 2010.

[5] J. G. Masek, et al., "North American Forest Disturbance Mapped from a Decadal Landsat Record," Remote Sensing of Environment, Vol. 112, No. 6, 2008, pp. 2914 2926. doi:10.1016/j.rse.2008.02.010

[6] E. P. Crist and R. C. Cicone, "Application of the Tasseled-Cap Concept to Simulated Thematic Mapper Data," Photogrammetric Engineering and Remote Sensing, Vol. 50, No. 3, 1984, pp. 343-352.

[7] C. Huang, B. Wylie, L. Yang, C. Homer and G. Zylstra, "Derivation of a Tasseled-Cap Transformation Based on Landsat-7 at-Satellite Reflectance," International Journal of Remote Sensing, Vol. 23, No. 8, 2002, pp. 1741-1748. doi: $10.1080 / 01431160110106113$

[8] R. J. Kauth and G. S. Thomas, "The Tasseled-Cap-A Graphic Description of the Spectral-Temporal Development of Agricultural Crops as Seen by Landsat," Proceedings, Symposium on Machine Processing of Remotely Sensed Data, West Lafayette, 1976, pp. 41-51.

[9] S. P. Healey, W. B. Cohen, Y. Zhiqiang and O. N. Krankina, "Comparison of Tasseled-Cap-Based Landsat Data Structures for Use in Forest Disturbance Detection," Remote Sensing of Environment, Vol. 97, No. 3, 2005, pp. 301-310. doi:10.1016/j.rse.2005.05.009

[10] W. B. Cohen and S. N. Goward, "Landsat's Role in Ecological Applications of Remote Sensing," BioScience, Vol. 54, No. 6, 2004, pp. 535-545. doi:10.1641/0006-3568(2004)054[0535:LRIEAO]2.0.CO ;2

[11] H. T. Harvey and Associates, "Marsh Plant Associations of South San Francisco Bay," Prepared for the City of San Jose, Environmental Services Agency, San Jose, 2003. www.sanjoseca.gov/Archive.aspx?ADID=1396

[12] E. B. Watson, "Marsh Expansion at Calaveras Point Marsh, South San Francisco Bay, California," Estuarine, Coastal and Shelf Science, Vol. 78, No. 4, 2008, pp. 593-602. doi:10.1016/j.ecss.2008.02.008

[13] J. Christian-Smith, "Managing for Multiple Benefits: Far- 
ming, Flood Protection, and Habitat Restoration in the Yolo Bypass Wildlife Area," Pacific Institute, Oakland, 2010.

[14] Jones and Stokes, "Napa River Salt Marsh Restoration Project Final Environmental Impact Statement," Sacramento, 2004.

[15] California State Coastal Conservancy (SCC), "Hamilton \& Bel Marin Keys Unit V Wetlands Restoration Project," California State Coastal Conservancy, Oakland, 2011.

[16] Phillip Williams \& Associates (PWA), "Bair Island Existing Hydrologic Conditions Assessment," Phillip Williams \& Associates, San Francisco, 2000.

[17] H. T. Harvey and Associates, "Bair Island Restoration Project Monitoring Plan," State Coastal Conservancy, Oak- land, 2004.

[18] Delta Risk Management Strategy (DRMS), "Phase 2, Building Block 3.1: Breach Dikes in Suisun Marsh 2011. http://www.water.ca.gov/floodsafe/fessro/levees/drms

[19] City of American Canyon, "Executive Summary/Letter of Intent City of American Canyon Wetlands Restoration Project," American Canyon, 1997.

[20] National Park Service (NPS), "Giacomini Wetlands Restoration: A Legacy for Tomales Bay," Department of the Interior, San Francisco, 2010.

[21] US Army Corps of Engineers (USACE), "Sonoma Baylands Wetland Demonstration Project-Demonstration Project Report and Environmental Assessment," US Army Corps of Engineers, San Francisco, 1994. 